\title{
DETERMINANT FACTORS OF THE INVESTMENT PERFORMANCE OF VOLUNTARY PENSION FUNDS IN ROMANIA
}

\author{
Victoria Şeulean ${ }^{1}$ \\ Luiza Moş ${ }^{2}$
}

\begin{abstract}
The goal of this paper is to give an overview of the voluntary private pension system. In the beginning it presents both the features and the legal framework that guide the functioning of these pension funds in our country and the basic descriptive data regarding the membership and the investments made by the funds. With the help of STATA, it carries on by analyzing the factors that determine the changes in the value of the fund unit and establishing the relationship that exists between the funds' total asset allocation and the value of the fund unit. Based on mathematical tools such as multivariate regressions it can be concluded that the investments made in deposits, government bonds and listed equity have the greatest impact on the performance of voluntary pension funds.
\end{abstract}

Key words: Voluntary private pension,investments, value of the fund unit

JEL codes: J32,G32

\section{Introduction}

The voluntary private pension system (pillar III), which is currently under implementation in Romania since 2007, is intended to support future pensioners, so they receive higher incomes in retirement. Participants' contributions are invested by pension fund managers based on the risk profile of the funds. What happens in practice? The monthly contributions of the participants become fund units in the participants' accounts. To calculate the amount existing in the account of each participant (or so-called personal assets), it suffices to multiply the number of fund units with the value of this unit at a specific day.

With the age of 60, if one paid at least 90 monthly contributions, one can benefit from voluntary pension, which will be paid by pension fund managers. If one has not attained the age of 60 years, or has not paid at least 90 monthly contributions to the pension fund, according to the legislation in force, at the time one has the right to voluntary pension, one receives the existing amount in the account, either in a single payment or in installments over a period of 5 years. (Law number 204/2006)

\section{Literature review}

The private pension system basically involves amounts invested on the long and very long term. In this context, it is natural the participants' concern for safe investment, so that at the retirement age they can enjoy the extra income. The private pension market is now strictly regulated and controlled. The institution supervising this market is the Private Pension System Supervisory Commission (PPSSC). Located under the control of Parliament, the institution was established by Government Ordinance no.50 of 9 June 2005, approved by Law no. 313 of 10 November 2005. Its mission is to protect the interests of those affiliated to the Pension System, by assuring an efficient

\footnotetext{
1 Faculty of Economics and Business Administration, University of the West, Str. J.H.Pestalozzi, nr. 16, 300115, Timisoara; victoriaseulean@yahoo.com

${ }^{2}$ Faculty of Economics and Business Administration, University of the West, Str. J.H.Pestalozzi, nr. 16, 300115, Timisoara; luizamos@yahoo.com
} 
functioning of this system and authorizing and supervising the activities carried out in the Pension System.

To ensure the smooth functioning of the private pensions market, among the duties of the PPSSC we can find:

- to prudentially supervise and secure the proper functioning of the private pension system

- to control the activity in the private pension system

- to control the relationships between the administrator and other administrators or companies, whenever the administrator transfers some of its attributions to the latter, which influence the financial situation of the administrator or are significant for conducting an efficient control

- to control the set up and transfer of contributions by the employer to the pension funds

- to issue norms regarding the private pension system(http://w4.csspp.ro/ro)

To increase the safety of voluntary private pension system, according to the law, every private pension fund assets are entrusted to storage facilities (credit institutions in Romania, approved by the National Bank of Romania in accordance with banking legislation, or branches in Romania of credit institutions authorized in one EU member state or belonging to the European Economic Area). These institutions are approved by the PPSSC for storage. Also, transparency is ensured by the pension fund managers' obligation to submit to the Private Pension System Supervisory Commission a monthly report on each investment fund. Also to protect the interests of the participants, a pension guarantee fund is set up. This ensures the payment of the participants and beneficiaries of pension funds, when the managers are unable to ensure them. (Şeulean V., 2003)

The maximum contribution that can be paid if one decides to participate in a pension fund is $15 \%$ of monthly gross wage income, or assimilated income. It is important to remember that the contributions to the pension funds are deductible within the limit of 400 Euro / fiscal year. One can participate simultaneously in several pension funds, as long as the monthly contributions do not exceed the $15 \%$ of gross monthly income, but naturally, it will require a higher level of fees. One has the option to suspend or terminate payment of contributions to a pension fund, requiring it to notify the fund administrator and the employer in writing at least 30 days before the date of suspension or termination of the contribution. There is always the option to resume contributions at any later date. It should be noted that if a termination of payment of contributions to the pension fund occurs (if one has not transferred to another fund), one will still retain rights and can benefit from the voluntary pension. The contribution to the pension funds may be divided between the participant and employer. This is done either by provisions included in the collective bargaining agreement, or if it does not exist, by a protocol signed by the employer with the representatives employee. (Law number 204/2006)

Asset allocation is a portfolio choice among broad investment classes. According to Swensen (2005), construction of a financial asset portfolio involves a combination of science and art. The science encompasses the application of basic investment principles to the problem of combining core asset classes in an efficient, cost effective manner. The art concerns the use of common-sense judgment in the challenge of combining incorporating individual characteristics into the asset allocation process.

Some studies (e.g. Ryan and Fabozzi 2003) show that post 2001 bankruptcies of US pension funds had their roots in the actuarial evaluation techniques rather than in asset losses, if long-term stock return is considered. According to Bader (2003) and McClurken (2006), post retirement benefit plans, pertaining to the 'first pillar' of a pension system, should not invest in high-risk financial instruments because this would lead to problems related to moral hazard and to the evaluation of 'superfluous risk'.

Other authors, such as Bikker, Broaders and Dreaw (2007) study the impact of stock market performance on the investment policy of Dutch pension funds and show that their investment 
policies are partially driven by the cyclical performance of the stock market. In addition they point out that pension funds respond asymmetrically to stock market shocks: rebalancing is much stronger after negative equity returns.

\section{Research methodology}

To better grasp the evolution the voluntary pension funds in Romania we start by an assessment of the dynamics of the participants and the investments. All the following analyses are done using data from the active voluntary pension funds: we consider the six funds that begin their activity in September $2007^{3}$ and continue with the 13 that are active at the end of July $2010^{4}$. Using data provided by PPSSC we get the following graph. It is not hard to see a significant increase in the number of members from September 2007, when there were 14543 participants until July 2010, when there were 207214, AZT being the fund with the most participants.

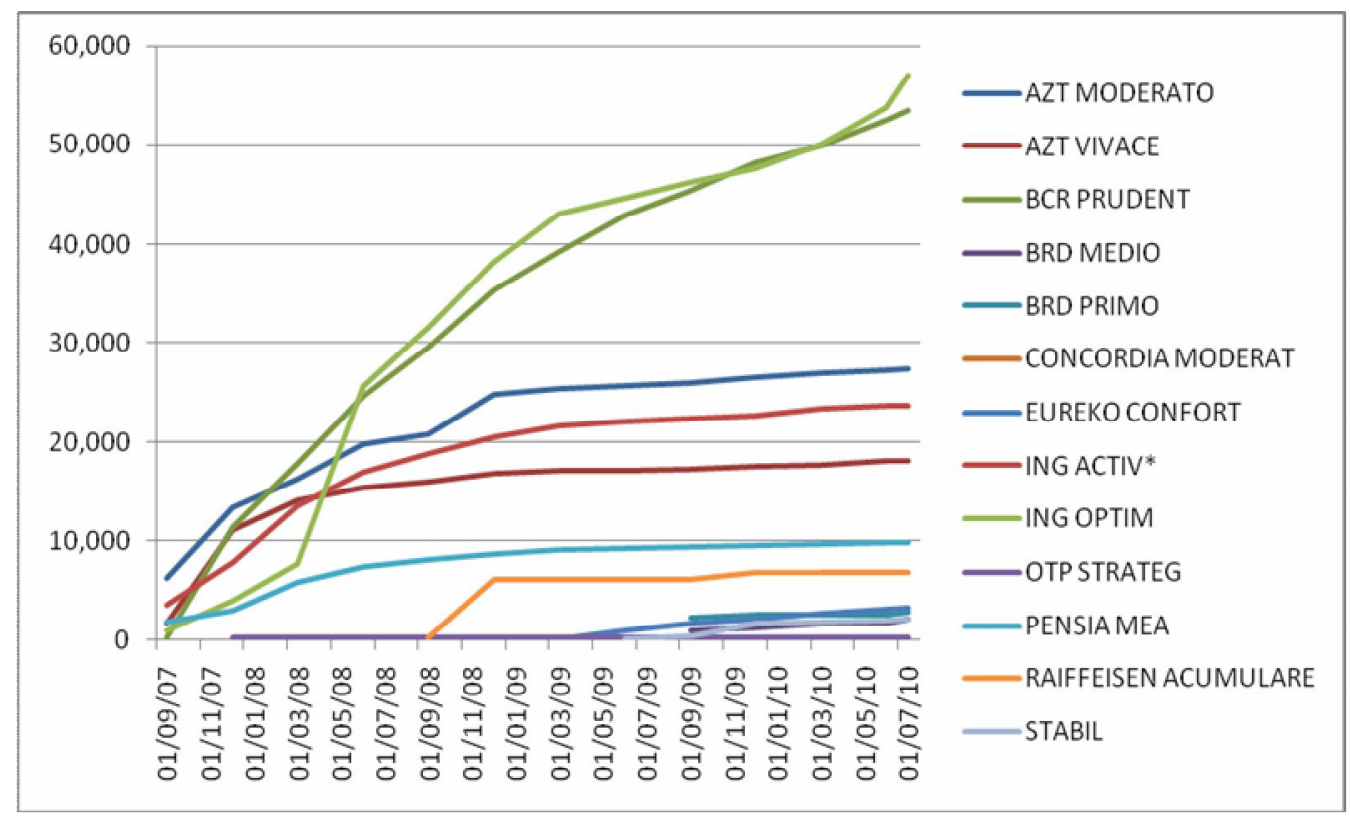

Fig. no. 1 - Dynamic of voluntary pension funds members

Further analysing the number of participants we consider the age differences. It can be concluded that the increase observed in the total number can be also seen in every one of the three categories considered (16-29 years, 30-44years and over 45years). It is no surprize that the largest part of participants are of age between 30 and 44 and the smallest part is the one of young people who are between 16 and 29 years old. When considering gender, there is no significant difference between the number of male and femal participants. Another important aspect that needs to be analized is the evolution of the funds' total fund allocation (fig. no.2).In the beginning, most of the investments were made in cash and deposits, later on the funds diversifing their investment portfolio but still addopting a safe investing strategy.

\footnotetext{
${ }^{3}$ AZT Moderato, AZT Vivace, BCR Prudent, ING Clasic, ING Optim, Pensia Mea

${ }^{4}$ AZT Moderato, AZT Vivace, BCR Prudent, BRD Medio, BRD Primo, Concordia Moderat, Eureko Confort, ING

Clasic, ING Optim, OTP Strateg, Pensia Mea, Raiffeisen Acumulare,Stabil
} 


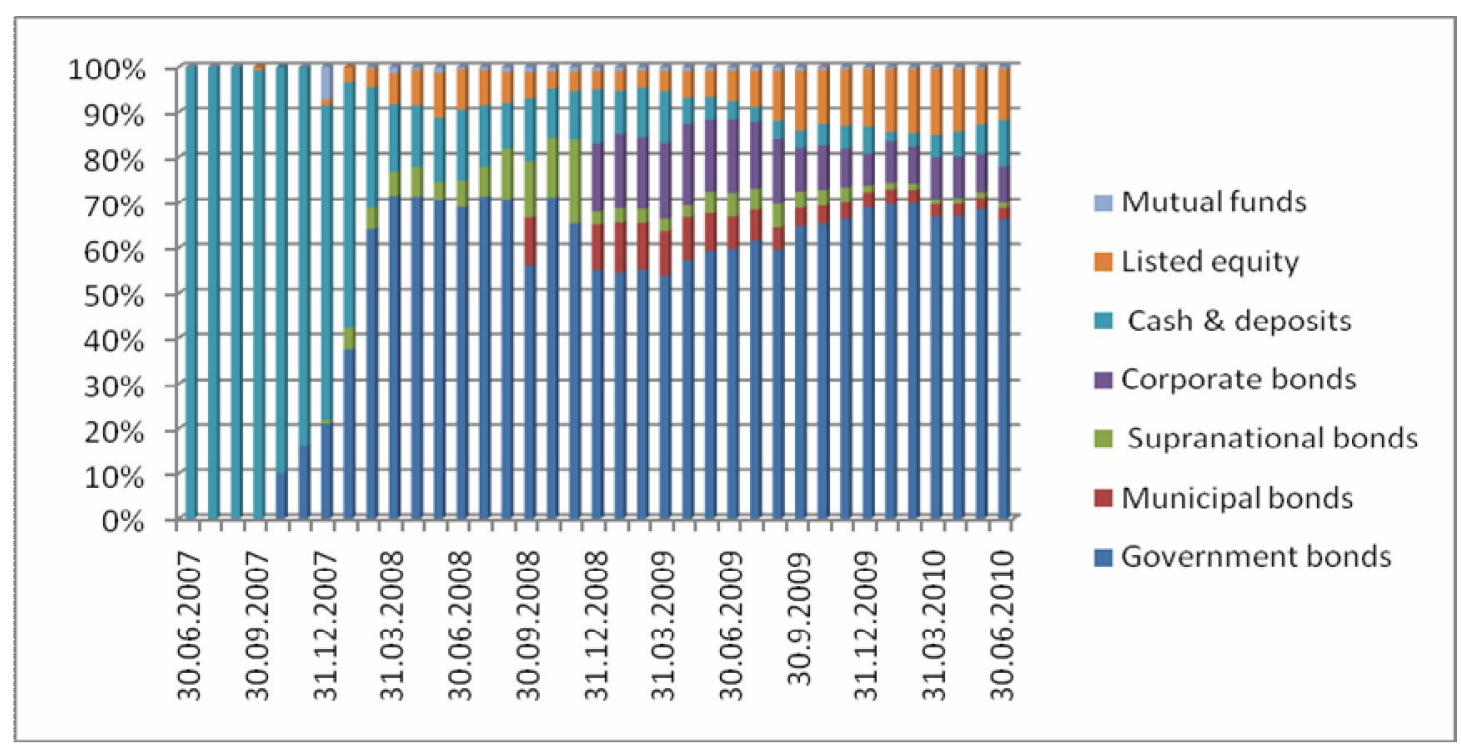

Fig. no. 2 - Voluntary pension funds' total asset allocation

A more in depth analysis of the relationship between the value of the fund unit and the assets in which the voluntary private pensions have invested is based on the multiple regression model. This type of analysis is currently widely used for empirical analysis in economics. Likewise, the method of ordinary least squares is popularly used for estimating the parameters of the multiple regression model (Woolridge J. M., 2000). Before estimating the parameters of the model some basic assumptions have to be considered. The assumptions provided by the specialized literature are: Linear model with respect to the parameters, random sampling, zero conditional mean, no perfect collinearity and homoskedasticity. The first assumption implies that the model can be written as $Y=\beta_{0}+\beta_{1} \cdot x_{1}+\beta_{2} \cdot x_{2}+\ldots+\beta_{n} \cdot x_{n}+u$ where $\beta_{0}, \beta_{1}, \beta_{2}, \ldots \beta_{n}$ are the unknown parameters (constants) of interest, and $u$ is an unobservable random error or random disturbance term. The random sampling assumption implies that the sampling from the population has been done in a random manner. The third assumption implies that the error $u$ has an expected value of zero, given any values of the independent variables; in other words, $\mathrm{E}\left(u \mid x_{1}, x_{2}, \ldots x_{n}\right)=0$. The forth assumption states that in the sample (and therefore in the population) none of the independent variables is constant and there are no exact linear relationships among the independent variables. The no perfect collinearity assumption concerns only the independent variables but says nothing about the relationship between the $\mathrm{u}$ and the explanatory variables. It is important to note that this assumption allows the independent variables to be correlated, as long as they are not perfectly correlated. If we did not allow for any correlation among the independent variables, then the multiple regression model would not be very useful for economic analysis. The last assumption means that the variance in the error term $u$ conditional on the explanatory variables is the same for all combinations of outcomes of the explanatory variables. If this assumption fails, then the model exhibits heteroskedasticity. The homoskedasty assumption is needed to justify the $t$ tests, the $F$ tests and the confidence intervals for the OLS estimation of the linear regression model. Many tests for heteroskedasticity have been developed over the years and we have chosen for our analysis the Breusch-Pagan test. The steps of this test are: estimating the original regression model by OLS and obtaining the squared OLS residuals for each observation, running a new linear regression of the squared OLS residuals on the entire explanatory variable and calculating the F-statistic based on the $\mathrm{R}$ squared determined on the previous strep. (Wooldridge J. M., 2000)

Considering all the above assumptions we conduct two analyses: one using the data provided by the Romanian Pension Funds' Association (http://www.apapr.ro) which is an aggregate 
view of the investments made by the managers of the voluntary private pension funds, and another one using the data provided by PPSSC which gives details about the individual investments made by each of the funds on a quarterly base.

The first analysis starts with a multiple regression model of the following form:

$$
F U V=\beta_{0}+\beta_{1} \cdot G B+\beta_{2} \cdot M B+\beta_{3} \cdot S B+\beta_{4} \cdot C B+\beta_{5} \cdot C D+\beta_{6} \cdot L E+\beta_{7} \cdot M F+u(1),
$$

Where $\mathrm{GB}=$ Government bonds,

$\mathrm{MB}=$ Municipal bonds,

$\mathrm{SB}=$ Supranational bonds,

$\mathrm{CB}=$ Corporate bonds,

$\mathrm{CD}=$ Cash and deposits,

$\mathrm{LE}=$ Listed equity,

$\mathrm{MF}=$ Mutual funds.

To correct for heteroskedasticiy (a chi2 value of over 3 determining the rejection of the homoskedasticity null for both data sets ), when estimating the regression we used the robust standard error estimates in stead of the normal standard errors. The results can be seen in the following figure:

\begin{tabular}{|c|c|c|c|c|c|c|}
\hline Linear regressi & & & & & $\begin{array}{l}\text { Number of obs } \\
\text { F( 5, } 32) \\
\text { Prob > F } \\
\text { R-squared } \\
\text { Root MSE }\end{array}$ & $\begin{array}{lr}= & 37 \\
= & 6723.56 \\
= & 0.0000 \\
= & 0.9986 \\
= & .44579\end{array}$ \\
\hline vUF I & Coef. & $\begin{array}{l}\text { Robust } \\
\text { Std. Err. }\end{array}$ & $\mathrm{t}$ & $P>|t|$ & {$[95 \%$ Conf. } & Interval] \\
\hline Gov_bonds I & 7.233518 & .6213847 & 11.64 & 0.000 & 5.967799 & 8.499237 \\
\hline Mun_bonds I & 11.23705 & 2.53145 & 4.44 & 0.000 & 6.080659 & 16.39345 \\
\hline Corporate_ s | & 16.77893 & 2.478706 & 6.77 & 0.000 & 11.72997 & 21.82789 \\
\hline Cash_depos s | & 10.22941 & .1580532 & 64.72 & 0.000 & 9.907466 & 10.55135 \\
\hline Listēd_equ y | & 39.87661 & 2.699314 & 14.77 & 0.000 & 34.37829 & 45.37494 \\
\hline
\end{tabular}

Fig. no. 3 - STATA Output for APAPR Data

In order to avoid multi-colliniarity, only six of the seven instruments were considered. After performing the analysis it was determined that, in this aggregate view, the supranational bonds and the investments made in mutual funds were not statistically relevant in explaining the changes in the value of the fund unit. When considering the overall significance test we get a $p$ value of zero which proves that the overall results are statistically significant. When looking at each of the five instruments, it is not hard to see that all of them, having a p value of zero, are highly significant at any level of personal significance. The value of the fund unit is influenced mainly by the changes in the return rates of the deposits made by the managers of the pension funds due to the massive investments made in the beginning as part of a safer investment strategy. Other instruments with a high influence on the value of the fund unit are the listed equity and the government bonds.

The other analysis that is worth considering is the one which establishes the investments that influence a change in the value of the fund unit by taking into account quarterly data provided by the PPSSC(http://w4.csspp.ro/ro), over the same period. The results obtained are slightly different, mainly due to the fact that two sets of data were use, obtained from different sources. The main difference is that now the supranational bonds become statistically significant, as it can be seen in figure no.4. 


\begin{tabular}{|c|c|c|c|c|c|c|}
\hline Linear regressi & & & & & $\begin{array}{l}\text { Number of obs } \\
\text { F( 6, 125) } \\
\text { Prob > F } \\
\text { R-squared } \\
\text { Root MSE }\end{array}$ & $\begin{array}{lr}= & 131 \\
= & 2317.01 \\
= & 0.0000 \\
= & 0.9884 \\
= & 1.2049\end{array}$ \\
\hline vuf I & Coef. & $\begin{array}{l}\text { Robust } \\
\text { std. Err. }\end{array}$ & $\mathrm{t}$ & $P>|t|$ & [95: Conf. & Interval] \\
\hline 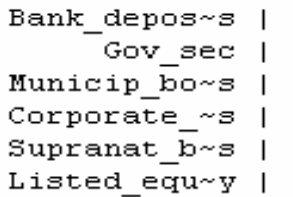 & $\begin{array}{r}10.01128 \\
10.5952 \\
9.756329 \\
5.388743 \\
22.88814 \\
21.48902\end{array}$ & $\begin{array}{l}.3149894 \\
.1943867 \\
2.641896 \\
1.862783 \\
6.518127 \\
1.740932\end{array}$ & $\begin{array}{r}31.78 \\
54.51 \\
3.69 \\
2.89 \\
3.51 \\
12.34\end{array}$ & $\begin{array}{l}0.000 \\
0.000 \\
0.000 \\
0.005 \\
0.001 \\
0.000\end{array}$ & $\begin{array}{r}9.387879 \\
10.21049 \\
4.527688 \\
1.702064 \\
9.987956 \\
18.0435\end{array}$ & $\begin{array}{l}10.63469 \\
10.97992 \\
14.98497 \\
9.075422 \\
35.78832 \\
24.93454\end{array}$ \\
\hline
\end{tabular}

Fig. no. 4 - STATA Output for PPSSC Data

From the figure above it can be seen that all six instruments influence the changes that occure in the value of the fund unit, even at a $1 \%$ significance level. The investments made in government securities have the greatest influence, followed by the deposits and the listed equity.

\section{Conclusions}

It is a known fact that the state pension systems are in an obvious decline, forcing governments to consider substantial reforms of pensions. Specifically, this means that in the relatively near future, private pensions will gain a key role in maintaining an acceptable living standard for citizens retired from active professional life. As a result, after the turmoil of the crisis will fade, the government should have as a priority to ensure a legal framework to encourage efficient participation and growth of private pension contributions.

The rate of returns obtained by the voluntary private pension funds are clearly affected by the risk preference adopted by the funds' managers through the investments they make. As it was shown, deposits, government bonds and listed equity have the most influence over the changes of the value of fund unit, and therefore over the returns. It should be noted that this model considers voluntary pension funds in Romania, which are a defined contributions type. Even though the number of participants to the voluntary private pensions is increasing every year, the returns of these funds are still not as high as the ones of the mandatory private pensions. This may change when the legal framework and the fees will be similar for the two pillars.

\section{References}

1. Bader, L.N., 2003. The case against stock in corporate pension funds, Society of Acturies Newsletter of the Pension Section, 51, 17-19.

2. Bikker J. A., Broeders D., Drew J., 2007. Stock market performance and pension fund investment policy: rebalancing, free flot or market timing?, DBN Working Paper

3. McClurken, 2006. Testing a moral Hazard Hypothesis in Pension Investment, Washington: Washington Univeristy.

4. Ryan R.J., Fabozzi, F.J., 2003. The pension crisis revealed. The Journal of Investing

5. Swensen D.F., 2005. Unconventional Success: A Fundamental Approach to Personal Investment, Free Press.

6. Şeulean V., 2003. Social protection and insurance, Mirton publishing house, Timişoara

7. Wooldridge J. M., 2000. Introductory Econometrics - A Modern Approach, South-Western College Publishing, USA

8. http://www.apapr.ro/images/STATISTICI/Seriitimp/p3\%20investpiata.xls

9. http://www.csspp.ro/date-statistice-pilonul-3

10. $* * *$ Law number $204 / 2006$ regarding voluntary privately managed pension funds 